\title{
SYSTEMIC INTERVENTION IN CREATIVE MANAGING PROBLEMS IN ENTERPRISES
}

\author{
Slavica P. PETROVIC \\ Faculty of Economics, University of Kragujevac, D. Pucara 3, \\ 34000 Kragujevac, Republic of Serbia \\ E-mail: pslavica@kg.ac.rs
}

Received 17 February 2013; accepted 07 August 2013

\begin{abstract}
The main purpose of this paper is to critically reassess the theoretical foundations and the methodological development of Systemic Intervention (SI) - as a new paradigm, based on theoretical and methodological pluralism - in order to determine the conditions, the ways and the results of its application in managing complex problems in enterprises. The employed instrumentarium is critical systems thinking, with its commitments to the critical awareness of the strengths and weaknesses of each research instrument for tackling problems in enterprises, the improvement of managing complex problems, and pluralism - respecting different interpretations of problem situations and enabling the combined use of research instruments. The main finding is that SI can underpin the process of structuring complex management problems in enterprises in a scientifically based and practically useful manner. In a scientific sense, the important implication of the conducted research is that it contributes to holistic understanding, conceptualizing and managing problem situations in enterprises. The relevant practical implication for managers is that - through a critical use of the SI methodology - they can creatively enhance the strategic management process in enterprises.
\end{abstract}

Keywords: complex and multifaceted management problems in enterprises, critical systems thinking, pluralism, new paradigm, Systemic Intervention, creativity.

JEL Classification: M10.

\section{Introduction}

In contemporary circumstances, management problems important for enterprises' survival and their development are the results of the simultaneous influences of many different economic, organizational, technical, technological, psychological, social, cultural, and political determinants. Therefore, they are characterized by great complexity, changeability in the time, interactivity, and numerous and various stakeholders with, as a rule, different interests, values, beliefs, opinions, various goals and means for achieving them, different knowledge and power, various perceptions and interpretations of a problem area under consideration, different participation in problem solving, different participation in making decisions and their implementation. 
Consequently, such problems should be observed and explored as problem situations, i.e. as the systems of complex and manageable problems (Petrovic 2012).

Effective and efficient dealing with complex and ambiguous management problems in enterprises implies, first of all, a reflection on the boundaries of research, i.e. the judgement about what - as essentially important - should be included in the exploration, and what - as less significant or irrelevant - may be regarded as marginal and be excluded from the research process. In the context of this relevant research area, there are the two key questions:

- Where should the boundaries be placed in exploring a problem situation? and

- What values manage the process of setting the research boundaries?

The answers to these questions indicate:

- The dimensions, variables and entities of the management problem that will be - as important - included in the exploration, and

- The actions that will be taken during the intervention in the problem situation in order to make an improving change in it.

So, through the process of setting the boundaries in the research of complex and multifaceted management problems in enterprises, the knowledge to be considered as appropriate and the people - individuals and/or group(s) - to generate this knowledge are determined.

For creative tackling this research problem, the contemporary critical systems thinking (Jackson 2003, 2010; Mingers, White 2010; Zhu 2011; Ulrich 2012a, 2012b) provides the corresponding conceptual and methodological framework through supporting:

- the critical awareness of the advantages and limitations of every single theory, methodology, method, technique, model for tackling problems in organizations,

- the improvement of prediction and control, the enhancement of mutual understanding between the stakeholders taking part in organizations, and the liberation of the power relations and learning, and

- pluralism - respect the different perceptions and interpretations of the problem situations in organizations and enable the mixed employment of the methodologies, methods, techniques for structuring the problem situations and solving the problems.

Depending on the approach to dealing with theoretical and methodological pluralism, the following proposals for the pluralism development can be singled out (Jackson 2000): pluralism as a meta-paradigm (Flood 2001), pluralism as post-modernism (Taket, White 1998), discordant pluralism (Gregory 1996), pluralism as critical systems practice (Jackson 2001, 2003, 2006, 2010, 2011), pluralism as a new paradigm.

Pursuant to its own ontological, epistemological and axiological assumptions and methodological development, Systemic Intervention (SI) (Midgley 1992, 1995, 1997a, 2000, 2001, 2003, 2011; Midgley, Ochoa-Arias 2001; Midgley, Pinzon 2011; Midgley, Cavana, Brocklesby, Foote, Wood, Ahuriri-Driscoll 2013), as a new paradigm, represents a pluralistic, critically systemic approach to management. Namely, relying on the ideas of process philosophy and the theory of boundary critique, SI endeavors to improve 
dealing with complex and ambiguous management problems in organizations through the corresponding methodology and the resulting Creative Design of Methods (CDMs).

Hence, the main research issue that has been addressed in this paper refers to the critical re-assessment of the theoretical foundations of SI and its methodological and methodical development in order to determine conditions, ways and results of using the SI methodology in managing complex and multifaceted problems in enterprises.

The main hypothesis of the paper is that SI, considering its own philosophical-theoretical foundations and methodology, can be used in critical-systemic tackling complex management problems in enterprises with the goal to creatively improve the management process and results of the enterprise's functioning.

In accordance with the determined research problem, aim and hypothesis, this paper is organized as it follows. Section 1 deals with the comprehensive review of the philosophical and theoretical foundations of SI. In Section 2, the key sub-processes of the SI methodology are developed. The main aspects of the CDMs are considered in Section 3. Finally, after the discussion of the results of the SI employment in the specific, complexpluralistic context of introducing a new product into the enterprise production program, within the concluding section, the attitudes concerning the hypothesis, implications and limitations of the research process, then relevant open issues as well as guidelines for further research are highlighted.

\section{Theoretical foundations}

The ideas of process philosophy and the theory of boundary critique are built into the methodology of SI (Jackson 2000; Midgley 1992, 1995, 1997a, 2000, 2003, 2011; Midgley, Ochoa-Arias 2001; Midgley, Pinzon 2011).

In process philosophy, an analytical primacy belongs to the process, rather than the content. The focus is on a process of making judgments about the boundaries of an analysis, i.e. of an intervention in a problem situation under consideration. The subjects (or agents/actors) and objects of the research process are understood as the contents that should be determined through the process of making judgment about the research boundaries.

The following two boundaries should be used when one deals with the subjects:

- The boundary defining the subject(s) who is(are) involved in the research and

- The boundary defining the broader system for generating the required knowledge. Process philosophy is responsible for the variety of possible systems for acquiring the knowledge of a problem area in question. At the same time, process philosophy is accountable for theoretical pluralism related to the numerous and various judgments about the research boundaries.

The assumptions of process philosophy about the analytical importance of the process as well as the necessity of theoretical pluralism differ from the assumptions that have been made by other paradigms. Consequently, it can be stated that process philosophy provides a basis for developing a new paradigm. Process philosophy challenges the dog- 
matic view that there is only one correct boundary for research that should be employed. Process philosophy endeavors to provide the foundations for appropriate theoretical pluralism allowing people to be in the research focus, or outside the focus, depending on the purposes as well as values pursued.

The theory of boundary critique has been derived from process philosophy. The critical consideration of the boundaries of a research process, i.e. an intervention, represents the main subject matter of this theory. It is about normative theory not dealing with the description of the aspect of a problem situation, but prescribing an appropriate course of action. If the boundaries of a research are crucial for generating knowledge, then the capability of thinking critically about different possible boundaries is of decisive importance.

It is argued that different values - that have been connected with different ideas about improvement in the problem domain - can result in placing the boundaries on different places in the research process. Accordingly, judgments about boundaries are closely associated with judgments about values.

The theory of boundary critique does not represent a general theory on boundaries. This theory is directly connected with endeavors to improve a systemic intervention in the management problem situation.

Connections between the reflection on research boundaries and the concept of improvement are relevant and direct. Something that can look like an improvement for the boundaries that have been set narrowly does not have to look like an improvement when the boundaries of research are broadened. This explicitly indicates that the process of setting research boundaries implies making judgments about values.

The boundaries of research (and intervention) ought to be considered as social or personal constructions. It further means that, through the process of boundary setting: a) knowledge that should be seen as appropriate, and b) the subjects - generating that knowledge and being interested in the results of endeavors to improve the system - are determined.

The theory of boundary critique implies both the participation of different stakeholders and the critical evaluation of the relevant ideas in relation to different value systems. In the theory of boundary critique, research boundaries are crucial for determining the way in which an improvement during the intervention in a problem situation will be defined and for the action to be taken during such an intervention.

Taking into account the ideas that have just been presented, it can be stated that there is a relevant relationship between the theoretical foundations of SI, as a new paradigm, and action research, as a theoretically based and practically useful approach to creative addressing complex management problems. Namely, in the process of action research (Midgley 2003, 2011; Friedman, Rogers 2009; Checkland 2010; Gill, Johnson 2010), certain changes in the problem situation have to be determined and provoked - the action, and through implementing these changes, which should result in an improvement, one should learn - the research. At the same time, through the ontological, epistemo- 
logical and axiological assumptions of SI, the conceptual framework strives to develop, within which theoretically argumented relations between the stakeholders, their knowledge, and the improving changes have been established.

\section{Methodology}

Process philosophy and the theory of boundary critique enable theoretical pluralism which, in turn, provides the basis for methodological pluralism, i.e. for developing and employing a broader methodology (Midgley 1997a, 2000, 2003). The development of such a methodology implies the determination of the two concepts:

- intervention and

- systemic intervention.

In principle, an intervention in a complex and multifaceted management problem can be defined as a conceived action of a subject - an individual person, a group, an organization, a community, etc. - with the aim of making an appropriate change in the problem situation. The key issue in the process of addressing the problem situation in which one wants to intervene is: Where should the boundaries set in the research process? Thinking about the boundaries of knowledge means, in fact, the consideration of options for the inclusion and exclusion of certain dimensions, variables, and entities of the problem situation.

Taking into account the content of the intervention concept and the identified relevancy of the issue of setting boundaries in the research process, a systemic intervention can be defined in the following manner: It is about a conceived action of the subject(s) aimed at making a change in the problem situation with regard to reflection on the boundaries (Midgley 2000: 129).

The concept of systemic intervention occupies the central position in the SI methodology. This methodology for critically systemic and pluralist intervention in management problem situations should facilitate addressing the issues of the inclusion, exclusion and marginalization of certain aspects, variables, and entities through the improvement in thinking about setting the boundaries of research i.e. intervention.

The methodology appropriate to systemic intervention in a management problem situation implies the three key sub-processes:

- critique,

- judgement, and

- action.

First of all, the agent in a problem situation has to think critically about the boundaries as well as to make choices between different alternative boundaries in the research process. To make judgements about the boundaries of research is only possible through the implicit or explicit use of theories and methods. The thinking which results in a judgment about boundaries is a form of action. Critical thinking about boundary judgments is of vital importance because the relevant consequences of different possible actions can be the subject matter of research only through the critique of the boundaries. 
The second sub-process of the SI methodology - labeled as judgment - refers to choices between theories and methods. Relying on theoretical and methodological pluralism, these choices have to be made by the agent. Through these choices, he/she actually manages the process of action in the problem situation. In this context of consideration, theoretical and methodological pluralism is of great importance.

Namely, if the understanding of a problem situation can be limited in many different ways, then each of alternative boundaries can suggest the use of a different theory. Vice versa, every theory implies particular boundary judgments and consequently the particular understanding of the problem situation.

At the same time, given the fact that different methodologies and methods embody different theoretical assumptions, methodological pluralism also becomes especially significant. Namely, choices between the boundaries of research as well as the theories suggest the methodological options - the methodologies and methods - corresponding to the concerned understanding of the problem situation. Vice versa, each methodology and method implies a particular theory.

Choice between theories and methods is a form of action, in the similar way as the reflection on the boundaries and making choices between the boundaries can be understood as an action. It is about an intervention in the present in order to shape a strategy for a future intervention (Midgley 2003).

The third sub-process of the SI methodology refers to an action in a problem situation with the aim of creating an appropriate improvement in it. The action can only be determined in local contexts and the improvement, analogously, should be designed as a temporary and local one. Namely, since different subjects can rely on different boundary judgements, as a result, the same thing that seems to be an improvement of the situation for one agent can seem to be quite an opposite one for the other.

The temporality and local contexts of improvements in complex management problems in organizations make the concept of a sustainable improvement as a particularly important one. In principle, an improvement in a problem situation can be determined as the generating of a desirable consequence through the intervention, and consequently a sustainable improvement can be defined as a lasting improvement that will not be followed by undesirable effects.

The three main sub-processes of the SI methodology are only separable in an analytical sense. As a result, critique, judgement and action are the subject matter of critical consideration.

\section{The creative design of methods}

The relevant part of the SI methodology is the Creative Design of Methods (CDMs) (Midgley 1997a, 1997b, 2000). It is about the research instrument supportive of methodological pluralism in an appropriate manner. The creative design of methods enables the diversity of the functionalist, interpretive, emancipatory and postmodernist systems methodologies and their associated methods (Jackson 2006) - available to 
stakeholders in the systemic intervention process to learn from them - to be employed in a theoretically and methodologically founded way. The CDMs provides an appropriate strategy for selecting, designing and combining the methods in the practice of dealing with complex and multifaceted management problems in organizations.

Relying on the corresponding philosophical, i.e. theoretical position, selecting, designing and mixing methods are in the focus of the CDMs. As a result, the CDMs is not meta-paradigmatic. As a significant part of the SI methodology, the CDMs is based on the ideas of process philosophy and the theory of boundary critique, whose assumptions differ from those made by other paradigms. Therefore, the CDMs embodies its own paradigmatic assumptions and does not put itself above all other paradigms.

Respectively, within the CDMs, methods - that can be derived from other methodologies - are interpreted through the methodology of the agent included in the systemic intervention process in a problem situation. So, the creative design of methods should be considered as the corresponding representation of a new paradigm within critical systems thinking.

Problematizing the idea about a simple methodological choice is of primary importance for the development of the CDMs. The starting point is the realization that problem situations - because of their complexity and ambiguity - imply the use of a variety of existing methods as well as the development of new ones. It is argued that it is more useful for the agent to think in the categories of the design of methods rather than in the categories of a simple choice between available methodologies.

In developing a creative design of methods, the agent starts with the understanding of the problem situation - which he/she wants to intervene in - in the categories of a dynamic set of the systemically interconnected issues expressing the purposes of the agent's intervention. Each of these issues/purposes can require that it should be discussed through using a different method, or a part of some method.

The purposes have not necessarily been determined as a complete set. They can evolve in accordance with unfolding events and the development of the understanding of the situation. The fact that interventions in management problem situations are implemented during the time and that various purposes can appear at different moments corresponds to process philosophy.

The second key idea is that methods differ from the sum of their parts. So, for a system of interconnected purposes, an appropriate system of various methods for achieving these purposes can be designed.

In the process of identifying the questions expressing the purposes and designing corresponding methods for achieving these purposes, the leading role belongs to the agent. The agent is the one to take responsibility for managing possible tensions resulting from different stakeholders' purposes and their interpretations (Midgley, Pinzon 2011).

The issue of setting the boundaries in the process of research is decisively important for the CDMs because the selecting, designing and/or combining of the methods are directly conditioned by the accepted boundaries. There are numerous methods that can be employed in order to conduct this critique of the boundaries. 
The two types of questions expressing the purposes of managing the selection and/or design of the methods can be identified:

- The questions about the boundaries; through dealing with these questions, the design of methods for singling out the relevant dimensions of a problem situation should be determined, and

- The questions about these dimensions; through tackling these questions, the design of methods for discussing the previously singled out dimensions of the problem situation should be determined.

The third type of questions related to the agent's knowledge can be identified. This type of questions concerns a gap in his/her knowledge of available theories, methodologies, methods. In relation to this, an appropriate model of learning has been developed (Midgley 2000). Based on the creative design of methods, this model is focused on learning about the strengths and weaknesses of different methods and different methodologies that can be (re)interpreted in the categories of the concerned methodological approach.

In a practical sense, it is useful to start from the set of questions expressing the agent's purposes in order to find a method or a system of methods for achieving these purposes. As a rule, it is about a variety of methods.

In the given context of using the CDMs, it is crucial that the consideration of several relevant aspects be made, relating to: the purposes of the methods, the principles of the methodologies which the methods are derived from, the theories which the methods development has originally been grounded on, the insights into the past practical results of employing different methods.

\section{Results and discussion}

The following, scientifically and practically relevant results of the conducted research can be identified.

In contemporary circumstances, when researchers and managers have to face the increasing complexity and heterogeneity of problems in enterprises, on the one hand, while, on the other hand, there is an increasing diversity and variety of theories, methodologies, methods, techniques, and models available for addressing business problems, SI represents an authentic, critical-systemic approach to management.

Relying on process philosophy, SI is focused on making critical judgments about the boundaries of research i.e. intervention in complex and multifaceted management problems in enterprises. The central position belongs to both the key stakeholders of the enterprise - owners, representatives of employees, customers, suppliers, financial institutions, political establishment, a broader environment - who are involved in the process of dealing with a strategic problem of the enterprise - for example, introducing a new product in the enterprise's production program - as well as the corresponding system(s) for acquiring knowledge required for the creative management of the problem situation. Challenging the opinion that only one boundary of research i.e. intervention in the strategic problem ought to be considered as correct, SI implies theoretical pluralism and recognizes the existence of various aims and values of the stakeholders involved in the 
process of structuring the problem situation. This directly indicates that the management process of complex problems in enterprises can substantially be underpinned by different theoretical knowledge (from economics, business economics, management, management science, information systems, sociology, psychology and so on) which researchers, consultants, and practitioners should have.

Derived from process philosophy, the theory of boundary critique endeavors to provide a basis for the determination of an improving action in the problem area in the enterprise. Namely, the systemic intervention strives to be determined (and implemented) through making judgments about the values of the enterprise's stakeholders as well as through a critical reassessment of the economic, organizational, technical, technological, psychological, social, political, cultural aspects and variables that have to be included in/excluded from the process of dealing with the complex-pluralist context of introducing a new product in the enterprise's production program. This directly points out the fact that, besides the individuals/groups to be involved in the process of structuring the strategic problem and knowledge to consider as appropriate, the relevant resultant of setting the research boundaries is the intervention itself as well as the possible advancement of the enterprise's functioning.

So, it is about the action aimed to make changes in the problem area in the enterprise with regard to the critical judgment about the boundaries of research. The intervention defined in such a manner requires the use of an appropriate methodology based on theoretical and methodological pluralism, which, through the three main sub-processes: critique, judgment, action, endeavors to help the enterprise's stakeholders to creatively manage strategic problems.

In the process of critical reflection on the boundaries of intervention in the problem situation, the key stakeholders - managers, consultants from the different areas, representatives of the owners and wider environment etc. - have to make choice between alternative boundaries. Since the process of making critical judgments about the boundaries of research and intervention implies relying on the appropriate theoretical, methodological, and methodical knowledge, the above-mentioned is explicitly indicative of the fact that stakeholders should use corresponding theory(-ies), method(s), technique(s), model(s) - for example, some of methodologies from the interpretive paradigm - Soft systems methodology, or Strategic assumption surfacing and testing, or Strategic options development and analysis etc., or from the emancipatory paradigm - Critical systems heuristics, then, some of their associated methods/techniques - for example, the rich picture, or the assumption rating chart, or cognitive mapping, or the twelve boundary questions, respectively.

Within judgment, it is necessary, with the help of experts from different scientific domains, to make the appropriate choices between available theories, methods, and models. These choices will implicitly influence the process of action in the problem situation. This directly points out that theoretical and methodological pluralism are crucial for this sub-process, in a sense that various perceptions of the strategic context of introducing a new product in the enterprise's production program suggest different boundaries of research and intervention, and consequently suggest different theories i.e. methodologies. 
In action, as the third sub-process of the SI methodology, it is about action in the problem situation that should result in an appropriate improvement of the concerned problem domain. This action should be designed for a local context, for example, from the standpoint of the enterprise market share, while, the resulting enhancement in the problem area of the enterprise is a local and temporary one, for example, to increase the enterprise market share in the specified time period. This indicates the importance of a sustainable improvement.

The CDMs, as a relevant research instrument of the SI methodology, allows researchers, consultants, and managers to learn from different functionalist, interpretive, emancipatory, post-modernist methodologies and their associated methods in the process of systemic intervention. From a practical point of view, this means that in the strategic context of introducing a new product in the enterprise's production program the different methods and techniques mentioned above - derived from different methodologies that can belong to the different paradigms - can be interpreted in the SI conceptual framework.

Assuming that there is no simple methodological choice, researchers and managers are focused on a variety of methods as well as the design of methods rather than on a choice between available methodologies. In such a manner, a relevant issue of incompatibility between paradigms on the theoretical level (Dando, Bennett 1981; Jackson 2011; Zhu 2011) can be avoided.

In the development of the design of methods corresponding to the problem situation in the enterprise, the stakeholders involved in the research process start from the appropriate understanding of the problem situation in the categories of systemically interconnected issues representing the purpose and aims of an intervention agreed through debate, and concerning the determinants of introducing a new product in the enterprise's production program - on the market of final products, on the market of production factors, in technique and technology, in the staff's qualification structure, in finance, etc. - as well as the main relationships between them.

The leading role in identifying the issues expressing the aims of a systemic intervention, in overcoming conflicts, in selecting, designing and/or combining the methods for determining the relevant dimensions of the problem situation as well as methods for discussing these dimensions belongs to the stakeholders. This indicates the conditionality of the success of a systemic intervention by theoretical, methodological, and methodical knowledge stakeholders should have.

\section{Conclusions}

The main motivation for the conducted research was to explicitly connect SI, as the particular theoretical-methodological development within critical systems thinking, with the endeavours to creatively improve managing strategic problems in enterprises. Consequently, the key task was to critically discuss the theoretical foundations of SI, its methodology and the CDMs as well as to examine some of the main aspects of its use in the specific complex-pluralist context of management problems in enterprises.

Based on the presented research and the identified results, the main hypothesis of the 
paper can be considered as confirmed. Relying on the powerful conceptual-theoretical framework as well as the founded methodological and methodical development, Si can in principle be argumentatively used in dealing with complex management problems in the different areas and kinds of organizations from within the public, private, and voluntaristic sectors, as evidenced its numerous applications (Midgley 2000; Cordoba, Midgley 2008; Paucar-Caceres, Espinosa 2011; Barros-Castro, Midgley, Pinzón 2015 etc.). Respectively, in combinations with different systems methodologies (for example, with Interactive planning, Critical systems heuristics, Soft systems methodology, Viable systems model) and/or their associated methods, the systemic intervention methodology can be tested and used creatively in different types and sizes of enterprises in the manufacturing, service and trade, with the aim of improving of their management process and overall business results.

The obtained research results explicitly indicate that, in relation to non-holistic approaches to management, SI represents a more appropriate, critically systemic research instrumentarium corresponding to the increasing complexity and variety of management problems, on the one hand, and the increasing diversity of theories, methodologies, methods, techniques, and models available for managing problems in enterprises, on the other. At the same time, compared to the other approaches to dealing with pluralism in critical systems thinking, SI focuses on combining methods, i.e. on developing a creative design of methods, and - doing so - overcomes addressing the open issues of combining methodologies belonging to different paradigms. Accordingly, as the new paradigmatic development in the critical Management science, SI substantially contributes to making scientifically based, socially responsible and practically useful choices in the management of enterprises in turbulent circumstances.

Thus, in a scientific sense, the important implication of the conducted research and the obtained results is that they contribute to holistic understanding and conceptualizing as well as creative managing problem situations in enterprises. At the same time, the relevant practical implication for managers is that - through a critical use of the SI methodology and the CSMs - they can effectively and efficiently enhance the strategic management process in enterprises.

The key limitation of the research presented in the paper reflects in the fact that the developed critical review of the conceptual, theoretical, methodological, and methodical aspects of SI has not been followed by the corresponding research of the ways and outcomes of an immediate use of the Systemic intervention methodology and an appropriate design of methods in the concrete business conditions of an existing enterprise.

Exactly this limitation will be the subject matter of our future research. Also, the following two open issues are singled out as important for further research: the problem associated with an expectation that stakeholders involved in the process of systemic intervention will have required knowledge, as well as the problem concerning the paradigmatic validity of methodological pluralism, pursuant the fact that many of the methods / methodologies have been developed within different paradigms, while each one of the paradigms is based on different assumptions about the relevant entities, the ways of acquiring knowledge, and the value systems. 


\section{Acknowledgements}

The presented results are part of a research project (The subproject: Marketing and Management Research as a Support to the Interdisciplinary Project Realization, No 41010) supported by the Ministry of Education, Science and Technological Development of the Republic of Serbia.

\section{References}

Barros-Castro, R. A.; Midgley, G.; Pinzón, L. 2015. Systemic intervention for computer-supported collaborative learning, Systems Research and Behavioral Science 32(1): 86-105. http://dx.doi.org/10.1002/sres.2220

Checkland, P. 2010. Researching real-life: reflections on 30 years of action research, Systems Research and Behavioral Science 27(2): 129-132. http://dx.doi.org/10.1002/sres.1019

Cordoba, J.-R.; Midgley, G. 2008. Beyond organisational agendas: using boundary critique to facilitate the inclusion of societal concerns in information systems planning, European Journal of Information Systems 17(2): 125-142. http://dx.doi.org/10.1057/ejis.2008.4

Dando, M. R.; Bennett, P. G. 1981. A Kuhnian crisis in management science?, Journal of the Operational Research Society 32(2): 91-103. http://dx.doi.org/10.1057/jors.1981.22

Flood, R. L. 2001. Local systemic intervention, European Journal of Operational Research 128(2): 245-257. http://dx.doi.org/10.1016/S0377-2217(00)00068-0

Friedman, V. J.; Rogers, T. 2009. There is nothing so theoretical as good action research, Action Research 7(1): 31-47. http://dx.doi.org/10.1177/1476750308099596

Gill, J.; Johnson, P. 2010. Research methods for managers. London: SAGE Publications Ltd.

Gregory, W. J. 1996. Discordant pluralism: a new strategy for critical systems thinking, Systems Practice 9(6): 605-625. http://dx.doi.org/10.1007/BF02169216

Jackson, M. C. 2000. Systems approaches to management. New York: Kluwer Academic/Plenum Publishers.

Jackson, M. C. 2001. Critical systems thinking and practice, European Journal of Operational Research 128(2): 233-244. http://dx.doi.org/10.1016/S0377-2217(00)00067-9

Jackson, M. C. 2003. Systems thinking: creative holism for managers. Chichester: John Wiley and Sons.

Jackson, M. C. 2006. Beyond problem structuring methods: reinventing the future of OR/MS, Journal of the Operational Research Society 57(7): 868-878.

http://dx.doi.org/10.1057/palgrave.jors.2602093

Jackson, M. C. 2010. Reflections on the development and contribution of critical systems thinking and practice, Systems Research and Behavioral Science 27(2): 133-139.

http://dx.doi.org/10.1002/sres.1020

Jackson, M. C. 2011. The multi-methodology debate: a response to Harwood, Journal of the Operational Research Society 62(4): 811-813. http://dx.doi.org/10.1057/jors.2010.167

Midgley, J. 1992. The sacred and profane in critical systems thinking, Systems Practice 5(1): 5-16. http://dx.doi.org/10.1007/BF01060044

Midgley, J. 1995. What is this thing called CRITICAL systems thinking?, in K. Ellis, A. Gregory, B. R. Mears-Young, G. Ragsdell (Eds.). Critical issues in systems theory and practice. New York, London: Plenum Press, 61-71.

Midgley, G. 1997a. Mixing methods: developing systemic intervention, in J. Mingers, A. Gill (Eds.). Multimethodology - the theory and practice of combining management science methodologies. Chichester: Wiley, 249-290. 
Midgley, G. 1997b. Developing the methodology of TSI: from the oblique use of methods to creative design, Systems Practice 10(3): 305-319. http://dx.doi.org/10.1007/BF02557900

Midgley, G. 2000. Systemic intervention: philosophy, methodology, and practice. New York: Kluwer Academic/Plenum Publishers.

Midgley, G. 2001. Systems thinking for the $21^{\text {st }}$ century, in G. Ragsdell, J. Wilby (Eds.). Understanding complexity. New York: Springer, 249-256.

Midgley, G. 2003. Science as systemic intervention: some implications of systems thinking and complexity for the philosophy of science, Systemic Practice and Action Research 16(2): 77-97. http://dx.doi.org/10.1023/A:1022833409353

Midgley, G. 2011. Theoretical pluralism in systemic action research, Systemic Practice and Action Research 24(1): 1-15. http://dx.doi.org/10.1007/s11213-010-9176-2

Midgley, G.; Ochoa-Arias, A. E. 2001. Unfolding a theory of systemic intervention, Systemic Practice and Action Research 14(5): 615-649. http://dx.doi.org/10.1023/A:1011977220479

Midgley, G.; Pinzon, L. A. 2011. Boundary critique and its implications for conflict prevention, Journal of the Operational Research Society 62(8): 1543-1554.

http://dx.doi.org/10.1057/jors.2010.76

Midgley, G.; Cavana, R. Y; Brocklesby, J.; Foote, J. L; Wood, D. R. R.; Ahuriri-Driscoll, A. 2013. Towards a new framework for evaluating systemic problem structuring methods, European Journal of Operational Research 229(1): 143-154. http://dx.doi.org/10.1016/j.ejor.2013.01.047

Mingers, J.; White, L. 2010. A review of the recent contribution of systems thinking to operational research and management science, European Journal of Operational Research 207(3): 1147-1161. http://dx.doi.org/10.1016/j.ejor.2009.12.019

Paucar-Caceres, A.; Espinosa, A. 2011. Management science methodologies in environmental management and sustainability: discourses and applications, Journal of the Operational Research Society 62(9): 1601-1620. http://dx.doi.org/10.1057/jors.2010.110

Petrovic, S. P. 2012. A critical systems metamethodology for problem situation structuring, International Journal of Decision Support Systems Technology 4(1): 1-13.

http://dx.doi.org/10.4018/jdsst.2012010101

Taket, A.; White, L. 1998. Experience in the practice of one tradition of multimethodology, Systemic Practice and Action Research 11(2): 153-168. http://dx.doi.org/10.1023/A:1022977301782

Ulrich, W. 2012a. Operational research and critical systems thinking - an integrated perspective. Part 1: OR as applied systems thinking, Journal of the Operational Research Society 63(9): 1228-1247. http://dx.doi.org/10.1057/jors.2011.141

Ulrich, W. 2012b. Operational research and critical systems thinking - an integrated perspective. Part 2: OR as argumentative practice, Journal of the Operational Research Society 63(9): 1307-1322. http://dx.doi.org/10.1057/jors.2011.145

Zhu, Z. 2011. After paradigm: why mixing-methodology theorising fails and how to make it work again, Journal of the Operational Research Society 62(4): 784-798.

http://dx.doi.org/10.1057/jors.2010.31

Slavica P. PETROVIC is currently Professor PhD at Business Economics and Management Department, Faculty of Economics, University of Kragujevac, the Republic of Serbia. The key areas of her scientific interest and research are systems methodologies for structuring management problems in enterprises, soft and critical Management Science, scientific research methodology. She is also the Editor-in-Chief of the scientific journal Economic Horizons. 